\title{
ĐÁNH GIÁ SỰ LIÊN QUAN GIŨ๋A MộT SỐ ĐẶC ĐIỂM VỀ HİNH ẢNH TRÊN CẮT LỚP VI TÍNH LỒNG NGỰC VÀ MÔ BỆNH HỌC CỦA U BIỂU MÔ TUYẾN ÚC
}

\section{Nguyễn Truờng Giang*, Nguyễn Văn Nam*, Nguyễn Ngọc Trung*, Lê Việt Anh *}

\section{TÓM TÁT}

Nghiên cứu trên 31 bệnh nhân có u tuyến ức, được phẫu thuật và có kết quả mô bệnh học là u biểu mô tuyến ức, so sánh đặc điểm hình ảnh trên phim cắt lớp vi tính lồng ngực trước mổ với các týp mô bệnh học của u biểu mô tuyến ức. Nghiên cứu được thực hiện tại Khoa Phẫu thuật lồng ngực-Tim mạch-Bệnh viện Quân y 103, từ tháng 10/2012-10/2014.

Kết quả: Típ $\mathrm{AB}$ nhiều nhất (51,6\%). Hình dạng là tròn được thấy trong tất cả các phân nhóm mô học; hình oval không thấy xuất hiện đối với típ B3; còn hình dải chỉ xuất hiện một lần trong týp $\mathrm{AB}$. Khối u týp $A$ và $A B$ thường có bờ đều (63\% và $69 \%)$. Khối $\mathrm{u}$ týp $\mathrm{B} 2$ và $\mathrm{B} 3$ thường có bờ không đều và có tỷ trong cao. Tất cả các u tuyến ức nhóm $\mathrm{B}$ đều có tình trạng vôi hóa kèm theo. Mức độ ngấm thuốc cản quang cũng là cao nhất ở các nhóm B2 và B3.

Đặc điểm về hình ảnh khối u tuyến ức trên phim chụp cắt lớp vi tính lồng ngực là yếu tố quan trọng và có ý nghĩa trong việc tiên lượng các týp mô bệnh học của u biểu mô tuyến ức trước mổ. Những đặc tính "ác tính" của khối u trên trên CT-scan là: Bờ không đều, tỷ trọng và độ ngấm thuốc cao, tình trạng vôi hóa.

Tù khóa: Cắt lớp vi tính, u tuyến ưc.

\section{EVALUATE THE RELATIONSHIP BETWEEN COMPUTED TOMOGRAPHY MANIFESTATION AND PATHOLOGICAL CLASSIFICATION OF THYMIC EPITHELIAL TUMORS}

SUMMARY: 31 histopathologically confirmed cases were collected for their pathological and CT characteristics and results were statistically compared between different pathological types of thymic epithelial tumors at Hospital no. 103, from 10/2012 to 10/2014.

Results: Tip AB is the most $(51,6 \%)$. Round shape is in all histologic subtypes; oval is not in B3; also plaque shaped appears only once in the $\mathrm{AB}$. Tumor types $\mathrm{A}$ and $\mathrm{AB}$ have smooth contour (63\% and 69\%). Tumor type B2 and B3 have irregular contour and hight degree of enhancement. All thymoma group types B have calcification status. The degree of contrast medium suffusion is also the highest in the group B2 and B3.

Characteristics of the thymic tumor on CT scans chest is important and meaningful in predicting pathological types of thymic epithelial tumors before surgery. The "malignant characteristics" of thymomas on chest CT-scan are: irregular contours, the hight degree of enhancement and the high contrastmedium suffusion, calcification status.

Key words: Computed tomography, thymoma.

\section{1. ĐẶT VẤN ĐỀ}

Các khối u tuyến ức chiếm khoảng 5-21,7\% các khối u trung thất và $47 \%$ các khối u nằm trong trung thất trước [3]. Kết quả điều trị cũng như tiên lượng bệnh phụ thuộc rất nhiều vào mô bệnh học của các khối u tuyến ức.

* Bộ môn-Khoa Phẫu thuật lồng ngục-Tim mạch-Bệnh viện 103Học viện Quân $Y$

Người chịu trách nhiệm khoa họ: PGS.TS Nguyễn Trường Giang Ngày nhận bài: 20/03/2015 - Ngày Cho Phép Đăng: 27/03/2015 Phản Biện Khoa họ: PGS.TS. Đặng Ngoc Hùng

PGS.TS. Bùi Đúc Phú 
Năm 2004, Tổ chức y tế thế giới (WHO) đã công bố bảng phân loại về mô bệnh học các khối u tuyến ức được sửa đổi từ bảng phân loại năm 1999. Trong đó, u biểu mô tuyến ức là loại có tỷ lệ cao nhất và chia làm 2 loại là u tuyến ức và ung thư biểu mô tuyến ức, dựa vào hình thái bản chất tế bào và mức độ ác tính. Phân loại các týp mô bệnh học u biểu mô tuyến ức có ý nghĩa quan trọng trong việc tiên lượng bệnh.

Hiện nay, chụp cắt lớp vi tính (CT-Scan) lồng ngực là phương pháp chẩn đoán các khối u tuyến ức trước mổ có giá trị được sử dụng phổ biến nhất, nhưng xác định được týp mô bệnh học của khối u tuyến ức thường chỉ được thực hiện sau mổ. Do vậy, vấn đề đặt ra là cần dự đoán các týp mô bệnh học của u biểu mô tuyến ức trước mổ dựa vào hình ảnh trên CT-scan, để góp phần quyết định chiến thuật điều trị cũng như tiên lượng bệnh.

Trên thế giới, đã có một số tác giả nghiên cứu vấn đề này, nhưng ở Việt Nam, chưa có tác giả nào công bố.

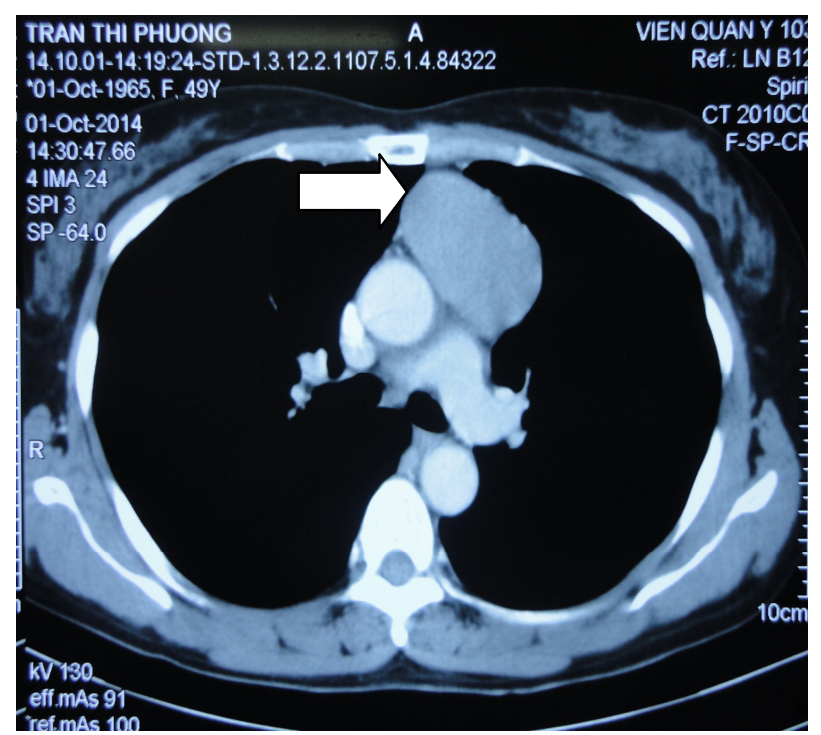

Hình 1a. Bò̀ đều
Vì vậy, chúng tôi tiến hành đề tài với mục đich: Đánh giá sụ liên quan giữa một số đặc điểm hình ảnh trên CT-scan lò̀ng ngục truớc mổ với các týp mô bệnh học của u biểu mô tuyến úc theo phân loại của WHO 2004.

\section{2. ĐỐI TƯợNG VÀ PHƯƠNG PHÁP NGHIÊN CÚU}

2.1. Đối tượng: Gồm 31 bệnh nhân chẩn đoán $\mathrm{u}$ tuyến ức bằng chụp cắt lớp vi tính lồng ngực trước mổ, được phẫu thuật và có kết quả mô bệnh học là u biểu mô tuyến ức tại Khoa Phẫu thuật lồng ngực-Tim mạch, Bệnh viện Quân y 103, từ tháng 10/2012-10/2014.

\subsection{Phương pháp nghiên cứu:}

Phương pháp nghiên cúu: Mô tả, so sánh

\section{Các chỉ tiêu nghiên cứu:}

*Nghiên cứu hình ảnh trên phim CT- scanner lồng ngục:

- Kích thước: Đo đường kính lớn nhất của khối u trên phim CT- scan lồng ngực.

Bờ của khối u được chia thành hai loại: đều hay không đều (Hình 1).

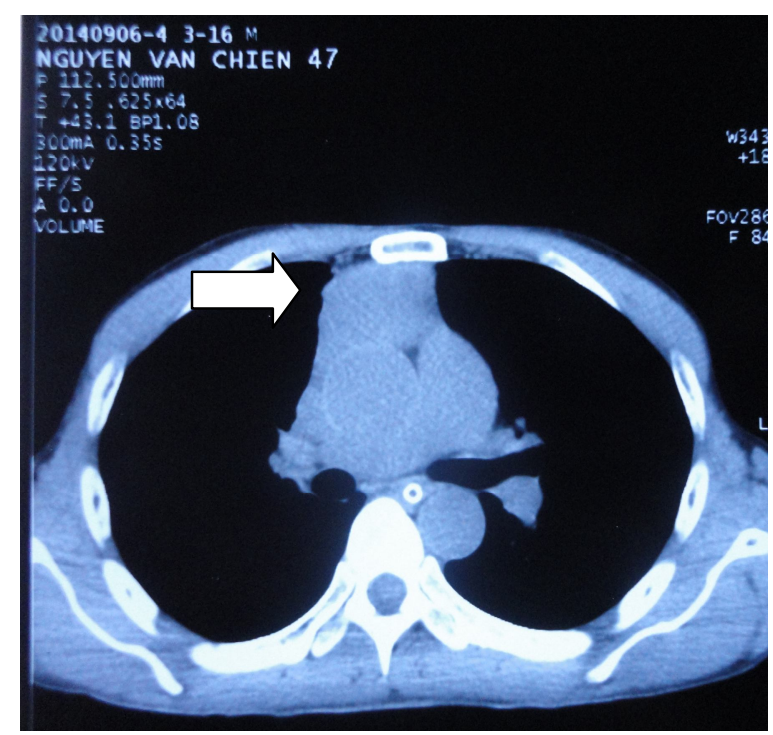

Hình 1b. Bờ không đều 
- Hình dạng: Chia thành ba dạng dựa vào tỷ lệ giữa chiều dài và chiều rộng của khối u: hình tròn, hình oval và hình dải (Hình 2).

+ Hình tròn: Tỷ lệ chiều dài/chiều rộng $\leq 1,5$

+ Hình oval: Tỷ lệ chiều dài/chiều rộng từ 1,5-3

+ Hình dải: Tỷ lệ chiều dài/chiều rộng > 3

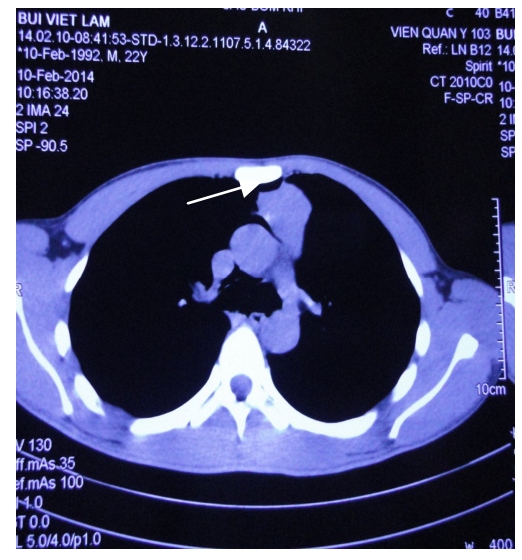

Hình 2a. Hình tròn

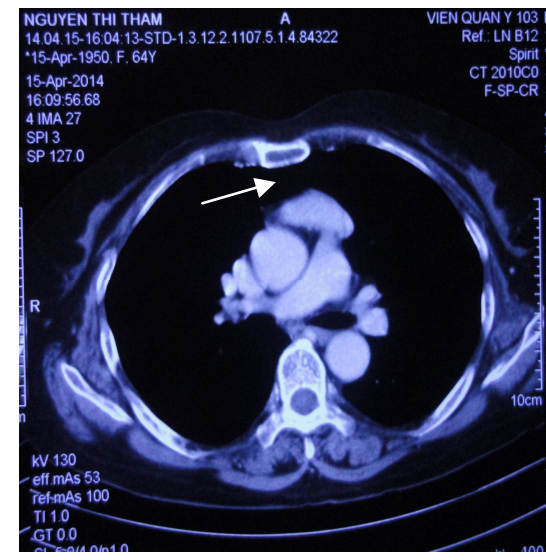

Hình $2 b$. Hình oval

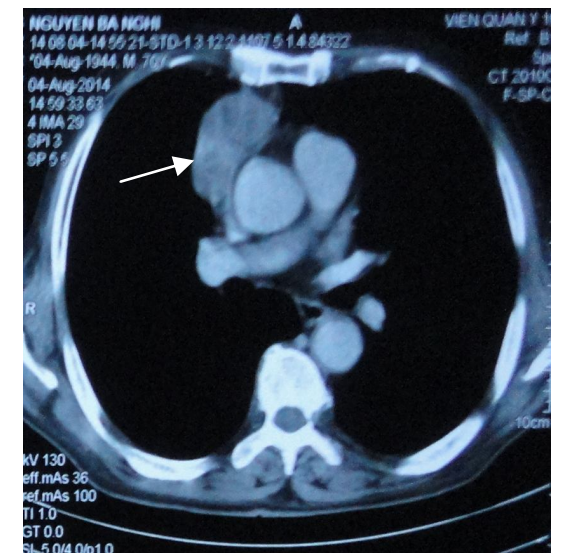

Hình 2c. Hình dải

- Đánh giá một số đặc điểm khác: Tỷ trọng, mức độ ngấm thuốc, vôi hóa, xâm lấn vào các cơ quan lân cận; tình trạng màng phổi.

* Nghiên cúu mô bệnh hoc:

Căn cứ vào phân loại các týp mô bệnh học u biểu mô tuyến ức của WHO năm 2004.

- U tuyến ức:

+ Týp A (tế bào hình thoi, thể tuỷ)

+ Týp AB (hỗn hợp)

+ Týp B1 (giàu lympho bào, lympho trưởng thành, ưu thế vỏ, dạng tổ chức)

+ Týp B2 (vỏ)

+ Týp B3 (biểu mô, không điển hình, dạng vảy, ung thư tuyến ức biệt hoá cao)

- Ung thư biểu mô tuyến ức (bao gồm cả các u biểu mô thần kinh nội tiết của tuyến ức).

2.3. Xử lí số liệu: Phần mềm Epi info 2000 .

\section{KẾT QUẢ NGHIÊN CÚU}

Bảng 1. Mối liên quan giữa kich thước lớn nhất và tỷ lệ týp mô học u biểu mô tuyến úc.

\begin{tabular}{|c|c|c|}
\hline Các týp mô bệnh học & Số bệnh nhân $(\mathbf{n = 3 1})$ & Kích thước trung bình $(\mathbf{m m})$ \\
\hline $\mathbf{A}$ & $8(25,8 \%)$ & $43,5 \pm 22,91$ \\
\hline $\mathbf{A B}$ & $16(51,6 \%)$ & $56,87 \pm 25,98$ \\
\hline B1 & $4(12,9 \%)$ & $47,75 \pm 16,37$ \\
\hline B2 & $2(6,5 \%)$ & $35,5 \pm 7,77$ \\
\hline B3 & $1(3,2 \%)$ & $57 \pm 0$ \\
\hline Ung thư biểu mô tuyến ức & 0 & 0 \\
\hline Tổng & $31(100 \%)$ & $50,87 \pm 23,26$ \\
\hline
\end{tabular}

Nhận xét:

Týp $\mathrm{AB}$ chiếm tỷ lệ cao nhất với 16 trường hợp $(51,6 \%)$, sau đó là týp $\mathrm{A}(25,8 \%)$, các týp nhóm $\mathrm{B}$ chiếm tỷ lệ thấp nhất, không gặp ung thư biểu mô tuyến ức. 
Kích thước lớn nhất là týp $\mathrm{AB}(56,87 \pm 25,98$ mm), nhỏ nhất là týp B2 $(35,5 \pm 7,77$ mm).

Bảng 2. So sánh một số đặc điểm khối u trên phim chưp cắt lớp vi tính lồng ngưc trước mổ và các týp mô học u biểu mô tuyến ức sau mổ.

\begin{tabular}{|c|c|c|c|c|c|c|}
\hline \multicolumn{2}{|c|}{$\overbrace{\text { Đăc điểm }}$ Týp mô học } & $\underset{(n=8)}{\mathbf{A}}$ & $\begin{array}{c}\mathbf{A B} \\
(n=16)\end{array}$ & $\begin{array}{c}\text { B1 } \\
(n=4)\end{array}$ & $\begin{array}{c}\text { B2 } \\
(n=2)\end{array}$ & $\begin{array}{c}\mathbf{B 3} \\
(n=1)\end{array}$ \\
\hline \multirow[b]{2}{*}{ Bò̀ } & Đều & $5(63 \%)$ & $11(69 \%)$ & $3(75 \%)$ & 0 & 0 \\
\hline & $\begin{array}{l}\text { Không } \\
\text { đều }\end{array}$ & $3(37 \%)$ & $5(31,3 \%)$ & $1(25 \%)$ & $2(100 \%)$ & $1(100 \%)$ \\
\hline \multirow{3}{*}{ Hình dạng } & Tròn & $6(75 \%)$ & $7(43,6 \%)$ & $2(50 \%)$ & $1(50 \%)$ & $1(100 \%)$ \\
\hline & Oval & $2(25 \%)$ & $8(50 \%)$ & $2(50 \%)$ & $1(50 \%)$ & 0 \\
\hline & Dải & 0 & $1(6,2 \%)$ & 0 & 0 & 0 \\
\hline \multirow{3}{*}{ Tỷ trọng } & Thấp & 0 & 0 & 0 & 0 & 0 \\
\hline & $\begin{array}{l}\text { Trung } \\
\text { bình }\end{array}$ & $6(75 \%)$ & $13(81 \%)$ & $2(50 \%)$ & 0 & $1(100 \%)$ \\
\hline & Cao & $2(25 \%)$ & $3(18,6 \%)$ & $2(50 \%)$ & $2(100 \%)$ & 0 \\
\hline \multirow{3}{*}{ Ngấm thuốc } & It $t$ & $2(25 \%)$ & $6(37,5 \%)$ & 0 & 0 & 0 \\
\hline & $\begin{array}{l}\text { Trung } \\
\text { binh }\end{array}$ & $6(75 \%)$ & $3(18,6 \%)$ & $2(50 \%)$ & 0 & 0 \\
\hline & Nhiều & 0 & $7(43,6 \%)$ & $2(50 \%)$ & $2(100 \%)$ & $1(100 \%)$ \\
\hline \multicolumn{2}{|l|}{ Vôi hóa } & $2(29 \%)$ & $2(12,5 \%)$ & $1(25 \%)$ & $1(50 \%)$ & $1(100 \%)$ \\
\hline \multicolumn{2}{|l|}{ Xâm lấn } & 0 & $1(6,2 \%)$ & $1(25 \%)$ & 0 & 0 \\
\hline \multicolumn{2}{|c|}{ Tràn dịch màng phổi } & 0 & $1(6,2 \%)$ & $1(25 \%)$ & 0 & 0 \\
\hline \multicolumn{2}{|l|}{ Phá hủy vỏ } & 0 & 0 & 0 & 0 & 0 \\
\hline
\end{tabular}

\section{Nhận xét:}

- Bờ:

+ Đều: Gặp ở các týp $\mathrm{B} 1, \mathrm{AB}, \mathrm{A}$ với các tỷ lệ tương ứng là $75 \%, 69 \%$ và $63 \%$, không gặp ở týp B2, B3.

+ Không đều: Gặp ở tất cả các týp, Cao nhất ở týp $\mathrm{B} 2$ và $\mathrm{B} 3$ với $100 \%$ các trường hợp.

- Hình dạng:

+ Hình tròn: Xuất hiện ở tất cả các týp, cao nhất ở týp $\mathrm{B} 3$ và $\mathrm{A}$.

+ Hình oval: Gặp cao nhất ở các týp AB, B1, B2 (50\%), không gặp ở týp B3.

- Tỷ trọng: Các týp $\mathrm{A}, \mathrm{AB}, \mathrm{B} 1$ gặp cả tỷ trọng trung bình và cao, týp B2 chỉ gặp tỷ trọng cao và týp $\mathrm{B} 3$ chỉ gặp tỷ trọng trung bình.

- Mức độ ngấm thuốc: Các týp $A, A B, B 1$ gặp ngấm thuốc ở cả 3 mức độ, týp $\mathrm{B} 2$ và $\mathrm{B} 3$ chỉ gặp ngấm thuốc mức độ nhiều.

- Hình ảnh vôi hóa: Gặp ở tất cả các týp, cao nhất là ở týp B3

- Dính : Gặp ở tất cả các týp trừ týp B3.

- Xâm lấn và tràn dịch màng phổi: Gặp ở týp $\mathrm{AB}$ và $\mathrm{B} 1$ với tỷ lệ tương ứng là $6.2 \%$ và $25 \%$.

- Không gặp trường hợp nào có hình ảnh phá hủy vỏ khối u.

\section{BÀN LUẬn}

\subsection{Tỷ lệ các týp mô bệnh học của u biểu} mô tuyến ức:

Theo phân loại của WHO 2004, u biểu mô tuyến ức được chia làm 2 loại: $U$ tuyến ức và ung thư biểu mô tuyến ức, $\mathrm{u}$ tuyến ức được chia làm 5 týp mô học là $\mathrm{A}, \mathrm{AB}, \mathrm{B} 1, \mathrm{~B} 2, \mathrm{~B} 3$. 
Việc phân loại này có ý nghĩa trong tiên lượng bệnh. Các týp $\mathrm{A}, \mathrm{AB}, \mathrm{B} 1$ được coi là các týp có nguy cơ ác tính thấp, các týp B2, B3 được coi là các týp có nguy cơ ác tính cao [4]. Trong nghiên cứu của Frank và cộng sự [2] xem xét và so sánh những nghiên cứu và tính toán khả năng sống trung bình 10 năm của từng týp mô học u biểu mô tuyến ức, có kết quả là $97 \%$ cho týp A, $95 \%$ cho týp $\mathrm{AB}, 92 \%$ cho týp B1, $81 \%$ cho týp B2, $62 \%$ týp B3, và $29 \%$ cho ung thư biểu mô tuyến ức, ung thư biểu mô tuyến ức có tiên lượng xấu nhất trong số 6 týp mô học.

Ngoài ý nghĩa tiên lượng bệnh, việc dự đoán mức độ ác tính trước mổ còn là yếu tố quyết định chiến thuật điều trị cũng như cách thức phẫu thuật (phẫu thuật nội soi hay phẫu thuật mở)

Kết quả của chúng tôi thấy týp $\mathrm{AB}$ có tỷ lệ gặp cao nhất $(51,6 \%)$, các týp có nguy cơ ác tính cao (B2, B3) chỉ chiếm 9,7\%. Kết quả của chúng tôi phù hợp với Tomiyama [8], nghiên cứu trên 53 trường hợp, có kết quả tỷ lệ týp $\mathrm{AB}$ cũng là lớn nhất (26,4\%). Nhưng Jeong [4] lại có kết quả các týp có nguy cơ ác tính cao $(\mathrm{B} 2, \mathrm{~B} 3)$ chiếm tỷ lệ cao nhất $(49,5 \%)$.

Trong số liệu nghiên cứu, chúng tôi không gặp ung thư biểu mô tuyến ức, trong khi các tác giả khác gặp tỷ lệ khá cao, Jeong [4] có kết quả 15/91 trường hợp $(16,5 \%)$, Tomiyama [8] gặp $8 / 53$ trường hợp $(15,1 \%)$ bị ung thư biểu mô tuyến ức. Có thể do số liệu của chúng tôi còn ít nên chưa gặp ung thư biểu mô tuyến ức.

4.2. Một số đặc điểm hình ảnh trên CTscan lồng ngực so với các týp mô học của u biểu mô tuyến ức.

* Sự liên quan giữa kích thước lớn nhất của khối u với các týp mô học.

Kết quả của chúng tôi thấy týp $\mathrm{AB}$ có kích thước lớn nhất (56,87 $\pm 25,98$ mm), týp B3 chỉ gặp 1 trường hợp và có kích thước khá lớn $(57 \mathrm{~mm})$, nhỏ nhất là týp B2 $(35,5 \pm 7,77$ mm), không gặp ung thư biểu mô tuyến ức.

So với một số tác giả khác, Tomiyama [8] nghiên cứu trên 53 trường hợp, có kết quả ung thư biểu mô tuyến ức có kích thước lớn nhất, nhỏ nhất là týp $\mathrm{A}$, nhưng không có sự khác biệt có ý nghĩa giữa ung thư biểu mô tuyến ức với các týp $\mathrm{AB}, \mathrm{B} 1, \mathrm{~B} 3$. Jung và cộng sự [5] cũng thấy rằng kích thước của ung thư biểu mô tuyến ức là lớn hơn so với các týp có nguy cơ ác tính thấp (A, $A B$, và $B 1)$ và u tuyến ức có nguy cơ cao (B2 và $B 3$ ), Liu [3] (2012) nghiên cứu trên 105 trường hợp, cũng cho kết quả ung thư biểu mô tuyến ức và các týp có nguy cơ ác tính cao (B2 và $B 3)$ thì có kích thước lớn hơn các týp có nguy cơ ác tính thấp $(\mathrm{A}, \mathrm{AB}$, và $\mathrm{B} 1)$. Như vậy, các tác giả này đều thống nhất các týp có nguy cơ ác tính cao như B2, B3 và ung thư biểu mô tuyến ức thì có kích thước lớn hơn các týp có nguy cơ ác tính thấp như $\mathrm{A}, \mathrm{AB}$, và $\mathrm{B} 1$.

Kết quả của chúng tôi chưa thống nhất với các tác giả trên, có thể vì số liệu nghiên cứu còn ít và chưa gặp ung thư biểu mô tuyến ức, mặt khác theo chúng tôi kích thước của khối u còn phụ thuộc vào tuổi bệnh ở tất cả týp mô bệnh học và độ ác tính không chỉ phụ thuộc vào kích thước của khối u, có thể có khối u kích thước nhỏ nhưng độ ác tính lại rất cao.

Do vậy, kích thước của khối u ít có giá trị tiên lượng bệnh mà chỉ có giá trị trong lựa chọn phương pháp điều trị.

* Sự liên quan giữa hình dạng của khối u với các týp mô học.

Số liệu của chúng tôi thấy: Hình tròn gặp ở tất cả các týp, cao nhất ở týp $\mathrm{B} 3$ và $\mathrm{A}$, hình oval gặp cao nhất ở các týp $\mathrm{AB}, \mathrm{B} 1, \mathrm{~B} 2$ (50\%), không gặp ở týp B3.

Trong nghiên cứu của Tomiyama và cộng sự [8] và Liu [3] thấy không có sự khác biệt về hình dạng của khối u giữa các týp mô học của u biểu mô tuyến ức.

Như vậy, Hình dạng của khối u không có ý nghĩa tiên lượng cho các týp mô bệnh học.

* Sự liên quan giữa bờ của khối u với các týp mô học.

Trong nghiên cứu của chúng tôi: Các týp có nguy cơ ác tính thấp $(\mathrm{A}, \mathrm{AB}$, và $\mathrm{B} 1)$ gặp cả bờ đều và không đều, nhưng bờ đều gặp cao hơn bờ không đều ở mỗi týp. Các týp có nguy cơ ác tính cao (B2 
và B3) thì chỉ gặp bờ không đều.

Kết quả này phù hợp với Jeong [4] và Tomiyama [8] có kết quả ung thư biểu mô tuyến ức và các týp $\mathrm{B} 2, \mathrm{~B} 3$ có tỷ lệ bờ không đều cao hơn các týp khác.Một số tác giả [6], [7] cho rằng, các đường viền hay bờ không đều được coi là sự xâm lấn vỏ của các khối u biểu mô tuyến ức.

Như vậy, đường nét bờ khối u không đều có thể định hướng là các týp u tuyến ức có nguy cơ ác tính cao hoặc ung thư biểu mô tuyến ức.

* Sự liên quan giữa tỷ trọng và mức độ ngấm thuốc với các týp mô học.

Tỷ trọng của khối u tuyến ức được chia làm 3 mức độ: Thấp, trung bình, cao (so sánh với tỷ trọng của cơ thành ngực)

Mức độ ngấm thuốc cũng được chia làm 4 mức độ: Ít (tăng 0-5 HU), vừa (tăng 5-10 HU), nhiều (tăng 10-20 HU), rất nhiều (tăng trên 20 HU). Mức độ ngấm thuốc thể hiện sự tăng tưới máu vào khối u.

Các khối u trong nghiên cứu của chúng tôi đều có tỷ trọng trung bình và cao. Mức độ ngấm thuốc cản quang nhiều gặp ở các týp B2 và B3, không có mức độ rất nhiều.

Kết quả của chúng tôi phù hợp với kết quả của Tomiyama [8] và Liu [3] cho rằng: Các týp mô học có nguy co ác tính cao thì có tỷ trọng cao và độ ngấm thuốc nhiều hơn.

* Sự liên quan giữa hình ảnh vôi hóa ở khối u với các týp mô học.

Hình ảnh vôi hóa trong nghiên cứu của chúng tôi gặp trong tất cả các týp $B$ và cao nhất ở $B 3$, kết quả này phù hợp với nghiên cứu của Tomiyama [8] và Liu [3] hình vôi hóa gặp ở các týp $B$ và tỷ lệ cao hơn ở B2, B3. Trong một số nghiên cứu khác [1], [5] thì thấy hình vôi hóa được tìm thấy trong cả hai loại u tuyến ức có xâm lấn và ung thư biểu mô tuyến ức. Rosado [7] cho rằng hình vôi hóa trong $\mathrm{u}$ tuyến ức thường là thẳng, mỏng, và ngoại vi và tương ứng với lắng đọng canxi trong các khối $\mathrm{u}$ nang của tuyến ức.

Như vậy, hình vôi hóa thường gặp ở các týp có nguy cơ ác tính cao là B2, B3.

* Sự liên quan giữa hình ảnh xâm lấn tổ chức xung quanh và tràn dịch màng phổi với các týp mô học.

Vấn đề liên quan giữa hình ảnh xâm lấn và tràn dịch màng phổi với các týp mô bệnh học u biểu mô tuyến ức còn chưa thống nhất giữa các tác giả.

Trong các nghiên cứu của Jeong [4]và Liu [3] có kết quả hình ảnh xâm lấn các thành phần trong trung thất và tràn dịch màng phổi gặp nhiều hơn ở các týp có nguy cơ ác tính cao là $\mathrm{B} 2, \mathrm{~B} 3$ và ung thư biểu mô tuyến ức. Đó là một yếu tố dự báo tiên lượng xấu.

Nhưng kết quả của Tomiyama [8] lại thấy tràn dịch màng phổi gặp cả ở các týp có nguy cơ ác tính thấp là $\mathrm{AB}, \mathrm{B} 1$ và cả ung thư biêu mô tuyến ức.

Trong nghiên cứu của chúng tôi, tình trạng là tràn dịch màng phổi và xâm lấn gặp 2 trường hợp ở týp $A B$ và $B 1$. Đặc biệt, chúng tôi gặp một trường hợp có hình ảnh khối u xâm lấn làm mất hoàn toàn hình ảnh của tĩnh mạch không tên, trong phẫu thuật thấy khối u kích thước lớn xâm lấn làm bít tắc hoàn toàn tĩnh mạch này, nhưng kết quả mô bệnh học là týp AB.

Do vậy, mối liên quan giữa hình ảnh xâm lấn và tràn dịch màng phổi với các týp mô bệnh học $\mathrm{u}$ biểu mô tuyến ức cần được nghiên cứu với số lượng lớn hơn để có nhận xét xác đáng.

\section{KẾT LUẦ N}

Với kết quả nghiên cưu ban đầu về mối liên quan giũa một số đặc điểm hình ảnh trên cắt lớp vi tính lò̀ng ngục và mô bệnh học u biểu mô tuyến ưc tại Bệnh viện Quân y 103 trong thờ gian tù 10/2012-10/2014, chúng tôi có nhận xét sau:

- Tý lẹ týp AB là cao nhất (51,6\%) trong các týp mô hoc của ung thu biểu mô tuyến úc.

- Có sụ liên quan giữa một số đặc điểm hính ảnh trên phim CT-scan lồng ngục với các týp mô bệnh hoc của ung thu biểu mô tuyến ưc: Týp $A B$ có kich thuớc lơn nhất $(56,87 \pm 25,98 \mathrm{~mm})$, các týp B2, B3 có tỷ lẹ bờ không đều cao hơn các týp khác, mức độ ngấm thuốc cản quang nhiều gặp ở các týp B2 và $B 3$, vôi hóa gặp trong tất cả các týp $B$ và cao nhất ở B3.

- Một số hình ảnh khối u trên trên phim CTscan lồng ngực liên quan đến các týp mô học có nguy cơ ác tính cao là: bò̀ không đều, tỷ trọng và độ ngấm thuốc cao, vôi hóa. 


\section{TÀI LIỆU THAM KHẢO}

1. Do YS, Im JG, Lee BH, et al. CT findings in malignant tumors of thymic epithelium. J Comput Assist Tomogr 1995; 19: $192-197$

2. Detterbeck FC. Clinical value of the WHO classification system of thymoma. Ann Thorac Surg 2006; 81: 2328-2334

3. Liu GB, Qu YJ, Liao MY, Hu HJ, Yang GF, Zhou SJ. Relationship Between CT Manifestations of Thymic Epithelial Tumors and the WHO Pathological Classification; Asian Pacific Journal of Cancer Prevention, Vol 13, 2012.

4. Jeong YJ, Lee KS, Kim J, Shim YM, Han J,

Kwon OJ. Does CT of Thymic Epithelial Tumors Enable Us to Differentiate
Histologic Subtypes and Predict Prognosis? AJR Am J Roentgenal 2004; 183: 283-289

5. Jung KJ, Lee KS, Han J, Kim J, Kim TS, Kim EA. Malignant thymic epithelial tumors: CT-pathologic correlation. AJR Am J Roentgenal 2001; 176: 433-439

6. Marchevsky AM, Kaneko M. Tumors of the thymus: thymoma. In: Marchevsky AM, Kaneko M, eds, Surgical pathology of the mediastinum. New York: Raven 1984; 58-116

7. Rosado-de-Christenson ML, Galobardes J, Moran CA. Thymoma: Radiological-Pathological Correlation. Radiographics 1992; 12: 151-198

8. Tomiyama $\mathbf{N}$, Johkoh $\mathrm{T}$, Mihara $\mathbf{N}$, et al. Using the World Health Organization Classification of thymic epithelial neoplasms to describe CT findings. AJR Am J Roentgenal 2002; 179: 881-886 